\title{
An Update on the Status of BVD Control and Eradication in Europe
}

Keywords: Bovine viral dianhoea virus; Control; Eradication; European; Surveillance; Diagnostics; Biosec urity

\begin{abstract}
Bovine Viral Dianthoea (BVD) is of major economic importance globally. Since the costs of BVD, both direct and indirect, have become increasingly recognised many European countries have evaluated the cost: benefit of implementing BVD control measures. Following on from the success of the first large-scale BVD eradication programmes, launched in the Scandinavian countries in the 1990's, many countries currently have national or regional, manda tory or voluntary era dic ation schemes underway. BVD control programmes are constantly evolving and adapting according to evaluation of their progress and to countryspecific factors. However there is no one source from which to review the current status of BVD control across Europe; this paper provides an up-to-date overview of BVD eradication in Europe.
\end{abstract}

\section{Introduction}

Bovine Viral Diarrhoea (BVD) is considered to be one of the most economically important diseases of cattle globally [1,2]. Much research has been published estimating the costs of BVD both at herd and national level, either as an endemic condition or due to an outbreak [3-5]. As the high financial costs of BVD virus (BVDV) infection have been increasingly recognised, decisionmakers in many European countries have opened consultation and commissioned research to evaluate whether control measures should be implemented [6].

Epidemiological modelling to provide cost-benefit analyses of BVDV control, in combination with evidence of the feasibility of eradication, have led to the majority of Western European countries either having achieved BVD-free status or having regional or national control programmes underway. However, in the absence of a panEuropean approach to BVDV control there is not one source from which to find current information regarding the status of BVD

\section{Journal of}

Veterinary Science \& Medicine

\section{Lucy V A Metcalfe*}

Boehringer Ingelheim Vetmedica GmbH, Germany

*Address for Correspondence

Lucy V A Metcalfe, Boehringer Ingelheim Vetmedica $\mathrm{GmbH}$, Binger Straße 173, 55216 Ingelheim am Rhein, Germany, Tel: +49 (6132) 77-171317; Mobil: +49 (151) 68948261; Fax: +49 (6132) 72-171371; E-mail: lucy.metcalfe@boehringer-ingelheim.com

Submission: 28 February, 2019

Accepted: 05 April, 2019

Published: 09 April, 2019

Copyright: $\odot 2019$ Metcalfe LVA, et al. This is an open access article distributed under the Creative Commons Attribution License, which permits unrestricted use, distribution, and reproduction in any medium, provided the original work is properly cited.

eradication within European countries. Therefore, the objective of this paper is to provide a consolidated overview of the current status of BVDV control in Europe (Figure 1). Therefore, the objective of this paper is to provide a consolidated overview of the current status of BVDV control in Europe.

\section{First systematic control measures}

The first large-scale BVD eradication programmes were launched in the Scandinavian countries in the 1990's, with all countries achieving BVD-free status within approximately 10 years $[7,8]$. Austria followed, utilizing a similar approach of initial bulk tank milk serological surveillance, followed by individual animal investigation in suspicious active BVDV farms, strict biosecurity and prohibited use of vaccination.

BVD seroprevalence before starting the programmes varied from approximately $1 \%$ in Finland to $50 \%$ in Denmark and, since BVD vaccines had never been used, BVDV-specific antibodies were always indicative of field BVDV infection [9]. The Scandinavian control programmes included a ban on the use of vaccines against BVD in

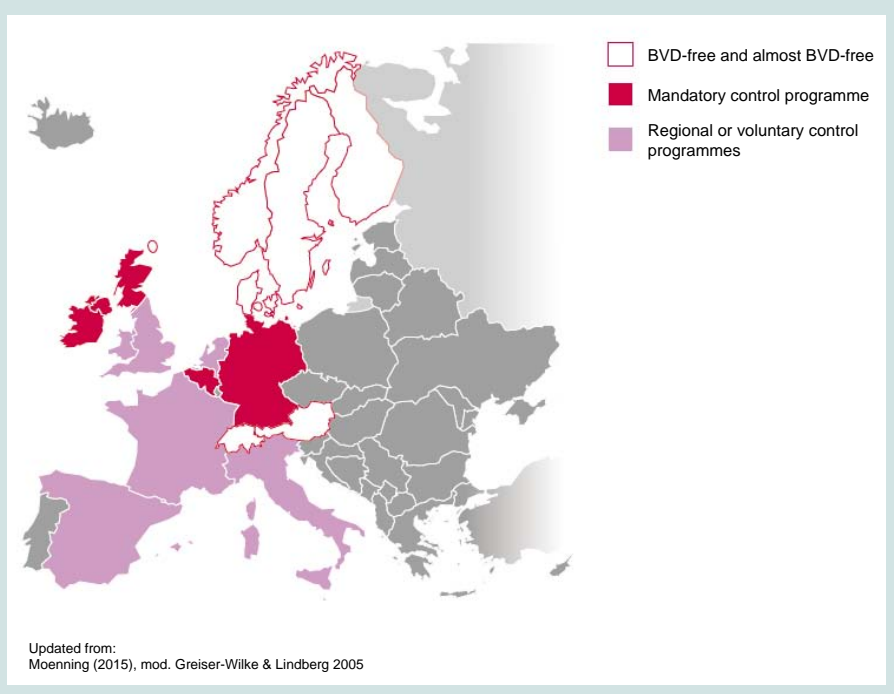

Figure 1: Current status of BVDV control in Europe. 
ISSN: $2325-4645$

Table 1: Diagnostic screening method options in Scotland.

\begin{tabular}{|c|c|c|c|}
\hline & Testing option & Dairy/beef & Test for Ab/Ag \\
\hline $1 \mathrm{a}$ & 5 animals between 9-18 months per separately managed group & Either & Antibody \\
\hline $1 b$ & 10 animals between 6-18 months per separately managed group & Either & Antibody \\
\hline 1c & If neither above are possible - 5 animals 18 months+ on holding since birth per separately managed group & Either & Antibody \\
\hline 2 & All calves & Either & Antigen \\
\hline 3 & All animals in the herd & Either & Antigen \\
\hline 4 & Bulk milk plus dry & Dairy & Antibody \\
\hline 5 & Quarterly bulk milk & Dairy & Antibody \\
\hline 6 & First lactation & Dairy & Antibody \\
\hline
\end{tabular}

order to enable serological surveillance. Research has demonstrated the interference of vaccination, with killed BVD vaccines, on interpretation of serological results [10].

In contrast, Switzerland chose to test the whole cattle population for BVD viral antigen within one year (2008-2009), culling all individuals considered to be Persistently Infected (PI) and banning vaccination. During the following four years, all newborn calves were tested for BVDV using ear notch samples. The rationale for this approach was the high initial seroprevalence (>80\% BVD antibody positive cattle in Switzerland) due to natural infection and widespread vaccination [9]. High antibody levels made it impossible to define a threshold over which herds could be suspected to have an active BVDV infection, thus warranting individual animal testing. The identification and removal of PIs reduced PI prevalence from $1.3 \%$ to $0.02 \%$ and, subsequently, a serological surveillance programme was put in place [11].

Unlike the Scandinavian countries, cattle density is high in Switzerland and there is frequent movement of cattle, and areas of shared summer grazing in mountain pastures. According to the Swiss database of animal disease, cases of BVD have been increasing in recent years. These isolated outbreaks are dealt with rapidly, by culling and movement restrictions and appear to be under control. There were 180 cases of BVD in 2018, which was $30 \%$ less than in 2017. In addition it has recently been announced that every farm will be checked for BVD during 2019.

\section{Scotland}

Following an earlier successful regional scheme in the Shetland Islands, a phased industry-led national control programme began in Scotland in 2010 with subsidized voluntary screening (termed Phase One). Mandatory screening of breeding herds commenced the following year (Phase Two) with six diagnostic screening methods available for the farmer to choose from (Table 1). Phase Three saw the implementation of control measures designed to reduce the spread of disease by stopping the movement of BVDV infected cattle and helping keepers to reduce the chances of buying-in disease.

Currently the Scottish BVD eradication programme is in Phase Four which includes restrictions on the movement of animals from 'not negative' herds, individual testing of animals brought in from untested herds, testing of calves from non-breeding herds within 40 days of birth and removal of all bulk milk testing options.

The persistence of BVDV antibodies in milk was found to be confounding the identification of active infection within dairy herds, lead to the decision to remove the option of bulk milk testing. Bulk milk serology represents a useful, cost-effective tool for ongoing surveillance of herds that have cleared BVDV however, historic infection and vaccination can render this diagnostic of limited value in herds that have recently eradicated BVDV [10].

The primary diagnostic used in Scotland is serological screening of representative young animals (known as the Young Stock Check Test, YSCT), in order to determine whether herds have been exposed to BVDV. The correct identification of each separately managed group is critical to the effectiveness of the YSCT. A management group consists of those animals that can freely achieve nose to nose contact with all other animals in the group. A representative number of young stock is sufficient providing all animals have been in close contact for at least two months, and this diagnostic has the advantage of indicating recent or current infection.

The plan is to implement Phase 5 in 2019, the details of which are currently under discussion.

\section{Germany}

Following a voluntary regional programme in the late 1980's in Lower Saxony, the official mandatory national control scheme was introduced in 2011. The programme is based on identification of PI animals, which is primarily achieved by testing of all newborn calves for BVDV using ear-notch samples. Vaccination is allowed and PI animals have to be destroyed.

In 2016, the German BVD regulation was amended to enable faster identification of PI calves. Currently, all calves must be tested within the first month of life using direct virus detection on earnotch samples, with ELISA or PCR. If a positive calf is to be retested this should be within 40 days and confirmed PI animals should be eliminated within 7 days. On farms where a PI is detected, no animal may leave the farm for 40 days (except directly to slaughter) and pregnant animals have restricted movement until after calving. Exceptions to these rules are animals that have been vaccinated against BVD in a way that grants foetal protection i.e. in advance of insemination, and pregnant animals that test negative after Day 150 of pregnancy. Based on negative experiences in Lower Saxony whereby major damage was caused by reintroduction of BVDV into PI-free herds which had become seronegative and therefore fully susceptible to BVDV infection, authorities in certain states subsidize, and can order, BVD vaccination [11].

The German programme has been very effective overall with a reduction in the prevalence of PIs from $0.48 \%$ in 2011 to $0.01 \%$ in 2017 [12]. In order to advance the final phase of eradication, BVDV isolates are sequenced at the National BVDV Reference Laboratory (FLI) to enable molecular typing to contribute to the identification of relationships between BVD outbreaks and uncover weak points in 
biosecurity.

\section{Ireland}

In Ireland, farmers and animal disease experts identified BVD as a disease to prioritize for action by Animal Health Ireland, a not for profit organisation with a remit to address endemic livestock conditions not subject to regulation. Prior to undertaking the eradication campaign, an economic analysis was commissioned which estimated the annual cost of BVD to the farming industry to be 102 million euros. This represented an approximate 10:1 Benefit: Cost ratio of a six year BVD eradication programme, based on three years of ear tissue testing of calves born followed by three years of lower intensity surveillance, considering both dairy and suckler farms [6].

Following an initial voluntary year, the national BVD eradication programme, supported by legislation, became compulsory in 2013 . Eradication is based on the identification of PI calves by testing ear tissue samples for antigen within 7 days of birth (including stillbirths and abortions); tissue-sample enabled official identity tags are used. The movement of cattle born since 2013, without a negative BVDV test, and of other animals with positive, inconclusive or suspect status is prohibited, except directly to slaughter.

Legislation does not require PI calves to be culled and the level of retention of PIs, particularly beef breed animals, was not predicted. To encourage prompt PI removal, limiting the risk of spread of infection, the Department of Agriculture, Food and the Marine has gradually increased the financial incentive to 185 euros for a dairy heifer. In addition, compensation is now only available when the PI is certified as removed within a restricted time period following identification. Herds retaining PIs are also placed under movement restrictions and neighbouring herds are notified of their proximity to PI animals.

Since programme inception, epidemiological research has been regularly conducted in order to inform decision-making. Herdlevel risk factors associated with the presence of BVDV have been identified and used to assist programme evolution and to inform communications with farmers. As reported elsewhere, introduction of animals that are either PI themselves or are pregnant with a PI foetus (Trojan animals) was found to be the most significant risk [13]. In addition, quantification of the risk of BVD spread between contiguous herds found that the odds of BVD positive calves being born in a herd when a neighbouring herd contained a BVD-positive animal almost doubled [14].

Since 2018 , in order to address the biosecurity risks identified, all herds that have one or more positive results for BVDV are required to undergo a BVD herd investigation. Funded under the Rural Development Plan, a local trained veterinarian performs the investigation, using the Irish Cattle Breeding Federation database. The focus is on animal origin and the location, movement, and contact of the dam within the window of susceptibility of PI production.

The programme has been successful with the prevalence of PIs reducing from $0.7 \%$ in 2013 to $0.06 \%$ in 2018 . The planned lower intensity serological surveillance phase has not yet been initiated.

Northern Ireland began a compulsory programme in 2016, after 3 years of voluntary testing. The Animal Health and Welfare Northern Ireland BVD eradication programme is similar to the Irish programme, variations accounted for, primarily, by differences in legislation and funding.

\section{Belgium}

Eradication began in Belgium in 2015 and, by law; all newborn calves (including aborted foetuses and stillborn calves) must be tested for viral antigen within 7 days, preferably by ear notch. PI calves and suspected PIs cannot leave the farm; entering pasture, being traded or participating at any gathering of animals is prohibited. There is mandatory testing of the dams of PIs, and dams of non-PI calves are designated 'unsuspicious by offspring'. Only BVD-free animals or 'unsuspicious by offspring' can move.

Subsequent changes to the legislation have included mandatory removal of PIs (2016), mandatory testing of purchased animals dependent on valid BVD status (2017) and awarding of a certified BVD-free herd status (2018).

Voluntary control measures: In recent years, national voluntary control programmes have commenced in The Netherlands, England and Wales. Stakeholders from the Dutch dairy and beef industry started the national BVD program in 2018. There is currently no legislation in place, however the dairy industry has made it mandatory for farmers to participate in order to deliver milk, and beef farmers are encouraged by the market situation and subsidy on BVD testing.

The GD (animal health service) is managing the certification and farmers can choose from four different routes towards BVDfree certification. Selection of the appropriate route depends upon herd BVD status, presence of antibodies in bulk tank milk or in young stock blood, or the preference to perform ear-notch testing of newborn calves. The routes differ in length of time and costs, and switching between routes is possible with additional testing, if appropriate. Within this programme, due to logistic problems, it is no longer mandatory to also test aborted foetuses and still born calves for BVDV however remains strongly recommended.

England has completed two years of an industry led programme and in Wales over $50 \%$ of farms has been screened in the first year of their programme.

Regional control plans have been in place in Italy for a number of years and Galicia in Spain started an official voluntary control programme in 2006, which is mandatory for members of farmers Association (ADS). France is due to start a national plan of eradication in 2019, following regional control efforts.

\section{Summary}

Systematic BVDV control, known as the general model of BVDV control, is based on three key elements: biosecurity to prevent introduction of infection into BVD-free herds, elimination of PI animals to reduce virus circulation and surveillance of BVD-free herds to enable early detection of reinfection [15].

In Europe, there are two main types of systematic control programmes in place, those allowing and those prohibiting vaccination. Belgium, Germany, Ireland and Scotland are following a similar approach of PI removal and optional vaccination. Vaccination should be considered to be a biosecurity measure, the ultimate aim of vaccination being to prevent foetal infection and the emergence of 
new PI calves. The majority of countries with systematic BVD control programmes without vaccination have reported severe economic damage from reintroduction of BVDV into cattle populations that have become seronegative, and vulnerable, following the removal of PIs [16]. This highlights the need for strict biosecurity to prevent reintroduction of infection and for this the education and continued motivation of farmers is key.

\section{References}

1. Houe H (1999) Epidemiological features and economical importance of bovine virus diarrhoea virus (BVDV) infections. Vet Micro 64: 89-107.

2. Loddo R, Francesconi V, Laurini E, Boccardo S, Aulic S, et al. (2018) 9-Aminoacridine-based agents impair the bovine viral diarrhea virus (BVDV) replication targeting the RNA-dependent RNA polymerase (RdRp). Bioorg Med Chem 26: 855-868.

3. Gunn GJ, Stott AW, Humphry RW (2004) Modelling and costing BVD outbreaks in beef herds. Vet J 167: 143-149.

4. Fourichon C, Beaudeau F, Barielle N, Seegers H (2005) Quantification of economic losses consecutive to infection of a dairy herd with bovine viral diarrhoea virus. Prev Vet Med 72: 177-181.

5. Carman S, van Dreumel T, Ridpath J, Hazlett M, Alves D, et al. (1998) Severe acute bovine viraldiarrhea in Ontario, 1993-1995. J Vet Diag Invest 10: 27-35.

6. Stott A, Humphry R, Gunn G, Higgins I, Hennessy T, et al. (2012) Predicted costs and benefits of eradicating BVDV from Ireland. Irish Vet J 65: 12

7. Hult L, Lindberg A (2005) Experiences from BVDV control in Sweden. Prev Vet Med 72: 143-148.

8. Rikula U, Nuotio L, Aaltonen T, Ruoho O (2005) Bovine viral diarrhoea virus control in Finland 1998-2004. Prev Vet Med 72: 139-142.

9. Moennig $V$ and Becher $P$ (2015) Pestivirus control programs: how far have we come and where are we going? Anim Health Res Rev 16: 83-87.

10. Booth R, Cranwell M, Brownlie J (2013) Monitoring the bulk milk antibody response to BVDV: the effects of vaccination and herd infection status. Vet Rec 172: 449.

11. Bachofen C, Stalder H, Vogt H, Wegmuller M, Schweizer M, et al. (2013) Bovine viral diarrhea (BVD): from biology to control. Berl Munch Tierarztl Wochenschr 126: 452-461.

12. Friedrich-Loeffler-Institut (2018) Statistik zur BVD-Bekampfung in Deutschland Quelle: Hi Tier pp: 1-4.

13. Graham D, Clegg T, Lynch M, More S (2013) Herd-level factors associated with the presence of bovine viral diarrhoea virus in herds participating in the voluntary phase of the Irish national eradication programme. Prev Vet Med 112: $99-108$.

14. Graham D, Clegg T, Thulke H, O'Sullivan P, McGrath G, et al. (2016) Quantifying the risk of spread of bovine viral diarrhoea virus (BVDV) between contiguous herds in Ireland. Prev Vet Med 126: 30-38.

15. Lindberg A, Alenius S (1999) Principles for eradication of bovine viral diarrhea virus (BVDV) infections in cattle populations. Vet Microbiol 64: 197-222.

16. Moennig V, Becher $\mathrm{P}$ (2018) Control of bovine viral diarrhea. Pathogens 7 : E29.

\section{Acknowledgement}

With thanks to technical colleagues within the various European countries who have provided country-specific information and translation. 